\title{
Imposto Predial e Territorial Urbano: tratando espacialmente desafios econômicos, sociais e políticos
}

Property tax: dealing spatially with economic, social, and political challenges

Matheus Pereira Libório[a] (D), Sandro Laudares[a] (D), João Francisco de Abreu[a] (D),

Petr Yakovlevitch Ekel[a] (D), Patrícia Bernardes[a]

[a] Pontifícia Universidade Católica de Minas Gerais (PUC Minas), Belo Horizonte, MG, Brasil

Como citar: Libório, M. P., Laudares, S., Abreu, J. F., Ekel, P. Y., \& Bernardes, P. (2020). Imposto Predial e Territorial Urbano: tratando espacialmente desafios econômicos, sociais e políticos. urbe. Revista Brasileira de Gestão Urbana, 12, e20190208. https://doi.org/10.1590/2175-3369.012.e20190208

\section{Resumo}

Esta pesquisa se insere no contexto da desigualdade urbana, que se revela, em parte, pela concentração da oferta de bens-serviços públicos em áreas mais favorecidas em detrimento de áreas menos favorecidas. Além de trazer evidências empíricas que confirmam esse entendimento, exploram-se alternativas para aumentar a progressividade dos tributos. Busca-se, assim, atribuir um imposto maior àqueles que se beneficiam mais da valorização imobiliária e do bem-estar produzido por tais bens e serviços. Logo, o objetivo desta pesquisa foi criar um mecanismo para extrair recursos de áreas mais favorecidas e investi-los, na forma de bens-serviços públicos, em áreas menos favorecidas. Para tanto, selecionaram-se variáveis relacionadas aos bens-serviços públicos (agrupamento hierárquico) e criou-se uma Variável de Síntese Bens-Serviços Públicos (VS-BSP) (análise de componentes principais). Os resultados revelaram que áreas menos favorecidas possuíam 2,54 e 2,52 vezes menos VS-BSP e renda, respectivamente. Com a nova alíquota do IPTU, que considera a progressividade tributária e a proporção da VS-BSP nos domicílios, pode-se atribuir uma alíquota 157\% maior para áreas mais favorecidas. Estima-se que essa alíquota possa contribuir para uma redução de $47 \%$ da diferença na oferta de bens-serviços públicos entre áreas mais e menos favorecidas.

Palavras-chave: Desigualdade urbana. Padrões espaciais. Bens-serviços públicos. Reforma tributária do IPTU.

\section{Abstract}

This research was inserted in the context of urban inequality, which is revealed, in part, by the concentration of public goods and services in favored areas, in the detriment of less favored areas. Besides providing empirical evidence that confirms this understanding, this work explored alternatives to increase the progressivity of taxes. Thus, it aimed to apply a higher tax on those who benefit most from property

MPL é economista, administrador, mestre em Geografia, doutorando em Administração, e-mail: m4th32s@gmail.com

SL é cientista da Computação, mestre em Engenharia de Sistemas de Informação e doutor em Geografia, e-mail: sandrolaudares@gmail.com JFA é geógrafo, economista, administrador, contador, mestre e doutor em Geografia e Pós-doutor, e-mail: jofabreu@hotmail.com

PYE é engenheiro eletricista, mestre em Sistemas de Fornecimento de Energia Elétrica, doutor e doutor Hábil em Centrais, Redes e Sistemas Elétricos junto ao Conselho de Ministros da URSS, e-mail: petr.ekel2709@gmail.com

PB é economista, mestre em Economia e doutora em Administração, patriciabernardes@pucminas.br 
appreciation and the welfare produced by such public goods and services. Therefore, this research goal was to create a mechanism to extract resources from favored areas, and to invest them as public goods and services in less favored areas. For this, variables related to public goods and services were selected (hierarchical cluster) and a Synthesis Variable of Public Goods and Services (VS-BSP) was created (principal component analysis). The results showed that less favored areas had 2.54 and 2.52 times less $V S$-BSP and income. With the new property tax rate, which considers tax progressivity and the proportion of the VS-BSP in households, it was possible to assign a 157\% higher rate to favored areas. Estimations showed that this new rate may contribute to a $47 \%$ reduction in the differences in the supply of public goods and services between the most and least favored areas.

Keywords: Urban inequality. Spatial patterns. Public goods and services. Property tax reform.

\section{Introdução}

A literatura de estudos urbanos revela que a influência das escolhas coletivas (Leven, 1976; Mark \& Goldberg, 1986; Lynch \& Rasmussen, 2004) e a concentração de investimentos em bens-serviços públicos em áreas mais favorecidas são elementos que agravam o problema da desigualdade urbana (Oates, 1969, 2001; Lopes \& Santos, 2010). Entre os diversos estudos que tratam desse problema, parte deles busca a compreensão e a explicação da desigualdade urbana por meio da identificação de padrões espaciais (Furtado, 2011; Netto et al., 2012; Cruz, 2012). Estudos recentes que utilizam novos modelos, métodos e técnicas de análise espacial (Alencar et al., 2013,2014) têm mostrado avanços no âmbito da compreensão e da explicação da desigualdade urbana, revelando, por exemplo, que a medida da desigualdade urbana varia conforme a escala de análise (Libório et al., 2018) e que a oferta de bens-serviços públicos está positivamente correlacionada à renda (Fonseca \& Aguiar, 2019) e às demais condições socioeconômicas dos domicílios (Carvalho et al., 2019).

Entretanto, ainda que ofereçam uma compreensão mais aprofundada do problema da desigualdade urbana, tais estudos pouco avançam na proposição de soluções objetivas para reduzi-la. Em consequência disso, áreas mais favorecidas (alta renda) continuam atraindo a maior parte dos investimentos em bens-serviços públicos, reforçando a desigualdade urbana (Carvalho et al., 2019). Desse modo, na literatura de estudos urbanos, há escassez de pesquisas que proponham soluções objetivas que corrijam as desigualdades na oferta de bens-serviços públicos, priorizando, portanto, investimentos em áreas desaparelhadas e sem infraestrutura (Souza, 1998). Nesse sentido, fazem-se os seguintes questionamentos: quais políticas públicas objetivas podem ser adotadas para alcançar a igualdade na oferta de bens-serviços públicos? Como implantar essas políticas em um cenário de recursos escassos?

Esta pesquisa explora alternativas de aplicação dos recursos públicos com mais justiça social, extraindo recursos de áreas mais favorecidas e investindo-os, em forma de bens-serviços públicos, em áreas menos favorecidas. Para isso, parte-se: (i) da hipótese de que é possível tornar bens-serviços públicos divisíveis para fins estritamente tributários, sem que essa divisibilidade implique na privatização deles ou na privação de acessá-los; e (ii) do princípio de que os cidadãos com maior poder econômico devem pagar mais impostos, uma vez que se beneficiam mais dos bens-serviços públicos do que os cidadãos mais pobres (Rezende, 2010).

Essa abordagem de pesquisa se fundamenta em duas justificativas. A primeira está relacionada ao princípio econômico do benefício individual dos bens-serviços públicos. Esse princípio propõe atribuir a cada cidadão o ônus equivalente aos ganhos obtidos dos bens-serviços públicos (Mankiw, 2016), isto é, atribui o ônus da concentração dos bens-serviços públicos aos cidadãos de regiões mais favorecidas, uma vez que estes tendem a se beneficiar mais da arborização urbana (Farias et al., 2016; Silva et al., (2016), das áreas verdes (Ferreira et al., 2019), de museus, teatros e de outros bens raros (Mendonça et al., 2019). A segunda justificativa está relacionada às externalidades positivas produzidas pela concentração dos investimentos em bens-serviços públicos em áreas mais favorecidas. Tais externalidades positivas 
ocorrem porque a presença de bens-serviços públicos está correlacionada à valorização dos imóveis (Hilber, 2017).

Ao explorar esse tema, busca-se trazer contribuições a inciativas anteriores (Smolka, 1991) que tentam transformar a tributação em instrumento efetivo de justiça social. Embora o Estatuto da Cidade (Brasil, 2008) tenha avançado no arcabouço legal, pesquisadores alertam que ainda é preciso colocar em prática tais instrumentos (Fernandes \& Alfonsin, 2014).

\section{Desigualdade urbana na alocação de bens-serviços públicos}

Se, por um lado, as cidades são lugares constituídos de elementos ativos com implicações e interdependências contínuas entre fenômenos (Netto et al., 2012), por outro se evidenciam nas cidades descontinuidades provenientes da repartição, especialização e concentração econômica (Carlos, 2011). Sustentadas pela dinâmica do mercado imobiliário, tais descontinuidades imprimem no espaço urbano a desigualdade socioeconômica e seus efeitos (Lynch \& Rasmussen, 2004). Há mais de meio século, a literatura vem mostrando que a concentração da oferta de bens-serviços públicos e privados de alta qualidade em áreas mais favorecidas tem intensificado os efeitos da desigualdade (Tiebout, 1956). Para reduzir os efeitos negativos da desigualdade, pesquisadores estão utilizando instrumentos de planejamento urbano de ordem política, legal, econômica ou técnica (Cruz, 2012). Esta pesquisa, ao colocar ênfase nos instrumentos técnicos, insere-se entre os estudos que buscam uma maior compreensão do problema da desigualdade econômica, seus efeitos e soluções.

Nessa abordagem, a maior compreensão da desigualdade tem como fundamento evidências que apresentem algum tipo de padrão espacial. Por exemplo, Netto et al. (2012) mostram a presença de correlações entre aspectos urbanos (morfologia dos imóveis, sociedade e espaço) com possíveis efeitos das desigualdades (nível de escolaridade e renda). Furtado (2011) trata da presença de padrões e similaridades entre a dinâmica do mercado imobiliário e as características do espaço urbano (aspectos sociais e econômicos). Lynch \& Rasmussen (2004) revelam relações de causa e efeito (positivas ou negativas) entre características dos domicílios (valor das propriedades ou proximidade geográfica das edificações) e espaço urbano que ocupam. Libório et al. (2018) trazem evidências de que a desigualdade econômica se torna mais evidente quando se altera a escala de análise, sendo menor na escala da cidade e maior na escala de Setores Censitários (SCs). Fonseca et al. (2017) mostram que os SCs com as maiores rendas tendem a concentrar a oferta de bens-serviços públicos. Fonseca \& Aguiar (2019) revelam ainda que existe uma correlação espacial entre as áreas de concentração de renda e as características demográficas das áreas de sua vizinhança. Carvalho et al. (2019) correlacionam a localização dos equipamentos e serviços públicos presentes nos SCs à condição socioeconômica dos domicílios. Maas et al. (2019) mostram que a oferta de serviços públicos de atenção primária à saúde se concentra em áreas menos favorecidas, mas que a oferta de serviços de saúde como um todo está em áreas mais favorecidas.

De modo geral, esses estudos se apoiam na ideia de que a identificação de padrões espaciais fornece informações que permitem reduzir diferenças características da desigualdade urbana (Cruz, 2012). Entretanto, ainda que a compreensão de padrões espaciais ofereça informações relevantes para o problema em questão, esses estudos não exploram soluções para reduzir desigualdades. Mas quais aspectos teóricos devem ser considerados em possíveis soluções?

Alguns estudos defendem que escolhas individuais segregam o espaço urbano, independentemente da presença de áreas fiscais ou políticas explícitas de habitação (Berry, 2001). Contudo, a literatura revela que áreas fiscais constituídas por imóveis de classes econômicas mais abastadas afastam escolhas individuais, uma vez que o valor dos imóveis dessas áreas depende da manutenção de sua morfologia (Leven, 1976). Lynch \& Rasmussen (2004) acrescentam que a constituição e a manutenção do padrão morfológico das áreas são resultado da escolha coletiva que, motivada pelo benefício da externalidade positiva, em decorrência da vizinhança abastada, eleva a tributação dos imóveis e expulsa os cidadãos 
menos favorecidos. Mark \& Goldberg (1986) explicam que, no longo prazo, os preços dos imóveis são influenciados com magnitudes e direções diversas em razão da tributação. Para os autores, a presença de áreas fiscais atrai/expulsa imóveis com base na sua morfologia provável. Mendonça et al. (2019) afirmam que esse movimento de atração/repulsão é proeminente em áreas mais favorecidas, fazendo com que a valorização imobiliária hipersegregue o espaço urbano. Sugere-se, assim, que a constituição de áreas fiscais que representam a dinâmica do mercado imobiliário e a desigualdade urbana esteja fortemente correlacionada com escolhas coletivas de longo prazo.

Entretanto, pesquisadores acrescentam que a compreensão dessa dinâmica (por exemplo, mercado imobiliário) também está relacionada ao processo de reprodução de investimentos em bens-serviços públicos no espaço urbano. Lopes \& Santos (2010) afirmam que o processo desses investimentos modifica o crescimento, o adensamento e a concentração econômica no espaço urbano. Oates (1969, 2001) atesta que as escolhas se fundamentam no valor de utilidade, ou seja, a escolha do local do imóvel de residência é um produto da utilidade dos benefícios produzidos pelos bens-serviços públicos presentes em seu entorno. Logo, entende-se que a quantidade destes está diretamente relacionada com o benefício incorporado aos imóveis. Assim, quanto maior a presença de bens-serviços públicos, maior é o benefício incorporado aos imóveis. Por isso, defende-se aumentar o imposto de áreas com maior bensserviços públicos, gerando os recursos para se investir em bens-serviços públicos de áreas menos favorecidas. Essa defesa apoia o argumento de Mankiw (2016), de que o bem público está associado ao princípio do benefício, e, por isso, cada cidadão deve assumir o ônus equivalente desse benefício. Defende-se nesta pesquisa que a cobrança equitativa do IPTU pode melhorar a distribuição da prosperidade econômica. Desse modo, explora-se a incorporação do ônus dos diversos benefícios produzidos pelos bens-serviços públicos, mais presentes nas áreas mais favorecidas, à alíquota do Imposto Predial e Territorial Urbano (IPTU).

\section{Imposto sobre a Propriedade Imobiliária (IsPI)}

Carrara (2006) revela que a primeira aparição do IsPI registrada no Brasil ocorreu em 1815. Denominado décima predial pela Coroa portuguesa, o imposto incidia sobre o rendimento líquido anual obtido por proprietários de prédios urbanos das cidades, vilas e lugares do Brasil (Carrara, 2006). No Brasil, assim como na maioria dos países da América Latina (Cesare, 2012), o IsPI é legislado pelo governo federal e administrado pelos municípios (Brasil, 1966). 0 fato gerador do IPTU é a propriedade (domínio útil ou posse de bem imóvel) localizada na zona urbana, sendo sua base de cálculo o valor venal da propriedade estipulado na Planta Genérica de Valores (PGV) do município (Sabbag, 2019).

Com base em dados do International Monetary Fund, o IsPI representa cerca de 0,6\% do Produto Interno Bruto (PIB) de países em desenvolvimento (Bahl \& Bird, 2018). Economistas vêm aconselhando países a aumentar a arrecadação do IsPI, afirmando que esse é um "bom imposto" (Slack \& Bird, 2015). Rezende (2010) cita três justificativas para mostrar porque o IPTU pode ser considerado um bom imposto: primeiro, a arrecadação do IPTU é relativamente imune às oscilações da atividade econômica de curto prazo; segundo, a imobilidade tributária do IPTU garante certa previsibilidade arrecadatória; terceiro, a impossibilidade física de transferência de propriedade elimina a evasão do pagamento do imposto pela mudança de domicílio. Carvalho (2014) afirma que reformas poderiam aumentar a participação do IPTU no PIB para até $2 \%$ ou $3 \%$. Para isso, o autor sugere a atualização da PGV, a revisão dos benefícios fiscais e a aplicação de taxas de imposto crescentes. 0 autor defende ainda que tais ações promovem a eficiência e a equidade na tributação dos imóveis, uma vez que geram recursos para financiar a infraestrutura urbana, transportes públicos, entre outros.

Contudo, Slack \& Bird (2015) citam seis razões para justificar porque é tão difícil realizar reformas no IsPI. A primeira razão é que o IsPI não é retido na fonte; logo, o cidadão tem maior consciência sobre IsPI, tornando-o um imposto impopular. A segunda razão é que o IsPI não está perfeitamente associado ao rendimento dos proprietários; isso faz com que o imposto imputado possa não refletir a situação 
econômica vigente do proprietário. A terceira razão é que, ao ser interpretado como uma cobrança pelos bens-serviços públicos, o IPTU não é um imposto inteiramente progressivo; dessa forma, defende-se que o imposto seja, na verdade, regressivo, uma vez que a habitação representa uma parcela maior dos gastos entre as famílias mais pobres. A quarta razão é que o IsPI não é corrigido automaticamente; assim, a base de cálculo do imposto não aumenta com a valorização anual dos imóveis. A quinta razão é que o IsPI não oscila dentro da capacidade contributiva dos contribuintes; isso faz com que ocorram grandes modificações na distribuição do sacrifício tributário dos contribuintes. Por fim, a sexta razão é que os contribuintes não gostam do cálculo do IsPI, não concordam com ele ou não o entendem (Slack \& Bird, 2015). Cesare (2012) acrescenta que países da América Latina encontram dificuldades adicionais em reformar o IsPI em razão dos maiores índices de: desigualdade de renda; informalidade de domicílios; diversidade na posse e ocupação da terra; e desinformações sobre o mercado imobiliário. Por tantas razões, Dornfest (2005) observa uma certa "revolta do contribuinte em relação ao IsPI".

Se, por um lado, reformas que propõem o aumento do IsPI são tão impopulares, por outro reformas que propõem a diminuição desses impostos tendem a aumentar as desigualdades. Pesquisadores mostram que, ao diminuir o imposto, aumenta-se o valor dos imóveis em áreas mais favorecidas, mas não se aumenta o valor dos imóveis em áreas menos favorecidas (Elinder \& Persson, 2017). Além disso, não é possível desconsiderar a relevância do IPTU na arrecadação municipal (Bahl \& Bird, 2018). Por isso, reformas no IPTU devem observar simultaneamente três fatores: 1) as dificuldades políticas, administrativas, jurídicas e financeiras dos munícipios (Carvalho, 2014); 2) a impossibilidade de se alterar a base de cálculo do imposto (valor venal), mas, ao mesmo tempo, a possibilidade de se alterar sua alíquota por lei ordinária municipal (Brasil, 1966); 3) a divisão equitativa da carga tributária (Rezende, 2010).

Nesse contexto, propõe-se somar o ônus equivalente aos ganhos obtidos dos bens-serviços públicos (Mankiw, 2016) à alíquota do IPTU e, assim, (i) não onerar os custos administrativos e políticos da reforma do IPTU (Carvalho, 2014); (ii) reduzir a relativa regressividade do imposto (Slack \& Bird, 2015); (iii) extrair recursos para financiar investimentos em infraestrutura urbana (Carvalho, 2014); (iv) reduzir as diferenças características da desigualdade urbana (Cruz, 2012); e (v) potencializar o IPTU como instrumento de justiça social.

\section{Tributação como instrumento de justiça social}

A justa repartição dos ônus e benefícios do processo de urbanização pode ser entendida pela perspectiva econômica como a justa distribuição da prosperidade econômica entre os membros da sociedade (Mankiw, 2016). Nesse contexto, um instrumento que tributa os benefícios provenientes de investimentos públicos realizados em espaço urbano pode ser promotor de equidade e justiça social. Smolka \& Amborski (2000) dão diversos exemplos do uso desse tipo de instrumento em países da América Latina (por exemplo, Colômbia, Chile e Argentina). No Brasil, esse instrumento é chamado de contribuição de melhoria. O capítulo II da Lei no 10.257, de 10 de julho de 2001 (Brasil, 2008), coloca a contribuição de melhoria como um "dos instrumentos da política urbana" do Brasil. Contudo, ainda que a contribuição de melhoria possa desempenhar um papel importante na repartição dos ônus e benefícios do processo de urbanização, esse instrumento nem sempre é utilizado (Sandroni, 2010). Sandroni (2010) afirma que é bem provável que os investimentos públicos no espaço urbano tenham sido apropriados integralmente pelos proprietários sem qualquer compensação para o estado. Assim, ao não atribuir o ônus dos investimentos, mas, ao mesmo tempo, beneficiar alguns poucos proprietários, o estado deixa de promover a justiça social.

Alguns pesquisadores defendem que não há como se promover justiça social sem "alterar as atuais regras do jogo imobiliário" (Smolka, 1991, p. 452). Outros lembram que "alterar as regras do jogo não garante que o jogo será jogado de acordo" (Fernandes, 2011, p. 313). 
Ainda que o Estatuto da Cidade (Brasil, 2008) reúna instrumentos de políticas públicas urbanas que avançam sobre o problema da justiça social, Fernandes \& Alfonsin (2014) chamam a atenção para a necessidade de colocar em prática tais instrumentos. Para os autores, esses instrumentos são o meio para se promover a justiça social e exercer a função social da propriedade. A função social da propriedade não implica somente no exercício da justiça social, mas na garantia da qualidade de vida e no desenvolvimento de atividades econômicas para os cidadãos (Brasil, 2008). Nesse âmbito, o capítulo I da Lei no 1510.257 (Brasil, 2008) dispõe, em suas diretrizes gerais, que "a política urbana tem por objetivo ordenar o pleno desenvolvimento das funções sociais da cidade e da propriedade urbana" (p.15) e considerar a "justa distribuição dos benefícios e ônus decorrentes do processo de urbanização" à sociedade (p.16). Mas como operacionalizar essa justa distribuição de ônus e benefícios?

Smolka (1991) sugere atualizar a PGV a partir das informações de operações imobiliárias. Ao fazê-la, o município reduz custos com a atualização da PGV e, ao mesmo tempo, aumenta a arrecadação com o IPTU. Segundo o autor, essa medida "tornaria redundante a necessidade de se cobrar a contribuição de melhoria". 0 problema é que esse instrumento não ajusta o IPTU de imóveis não envolvidos em operações imobiliárias, mas é uma contribuição acadêmico-pedagógica que traz à mesa o debate fiscal no âmbito do planejamento urbano como meio de se realizar uma política social (Smolka, 1991). A presente pesquisa se insere nesse debate, propondo um instrumento de ajuste fiscal para promover a justiça social.

\section{Materiais e métodos}

Esta pesquisa tem caráter exploratório, consistindo-se em um estudo de caso, tendo como unidade de análise a cidade de São Sebastião do Paraíso (SSP), em Minas Gerais (MG). Os materiais se resumem aos microdados do censo de 2010 e à malha dos SCs urbanos (código-situação-SC=01) (IBGE, 2010). Todos os 13 dados do entorno presentes no censo foram considerados incialmente: identificação do logradouro, iluminação pública, pavimentação, calçada, meio-fio/guia, bueiro/boca de lobo, rampa para cadeirante, arborização, rede geral de distribuição de água, esgotamento sanitário da rede geral de esgoto ou rede pluvial, lixo coletado diretamente por serviço de limpeza, lixo acumulado nos logradouros e esgoto a céu aberto. Foram utilizadas ainda as variáveis: número de domicílios e rendimento nominal mensal. Os métodos e técnicas análise de agrupamento hierárquico, matriz de correlações, normalização de variáveis e Análise de Componentes Principais (ACP) foram operacionalizados nos softwares Ninna Cluster, Ninna PCA e Microsoft Excel. Os mapeamentos foram produzidos no software QGIS.

\section{Área de estudo}

A cidade de SSP (Figura 1) faz parte de um conjunto de 153 municípios de Minas Gerais com população entre 20 mil e 100 mil habitantes (IBGE, 2010). Municípios com essa faixa de população têm na arrecadação do IPTU sua principal fonte de recursos (Longo \& Lima, 1982; Rezende, 2010). Ao mesmo tempo, a administração pública desses municípios tem mais dificuldades políticas, administrativas, jurídicas e financeiras para melhorar a arrecadação do IPTU (Carvalho, 2014). 

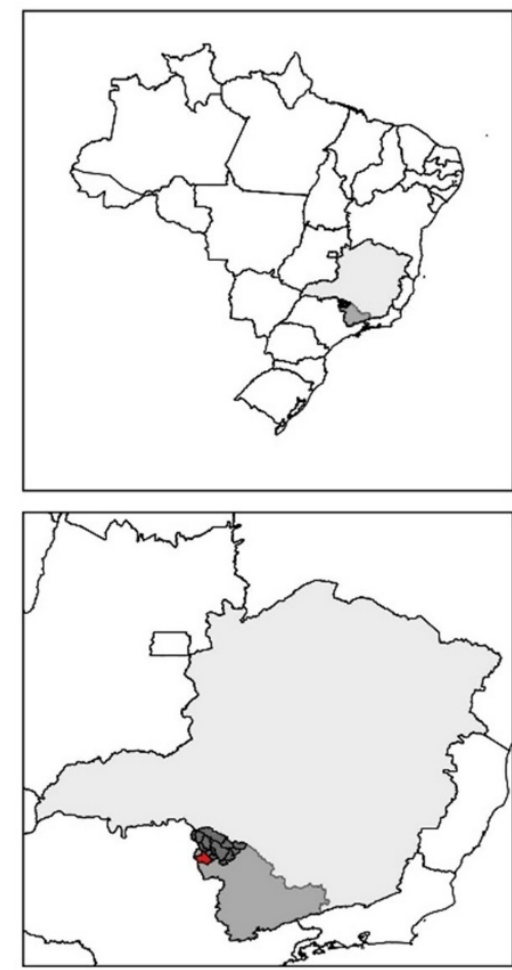

Localização de São Sebastião do Paraíse

Sảo Sebastião do Paraíso

Micro Rcigào - Pas

Minas Gerais

$\square$ Brasil

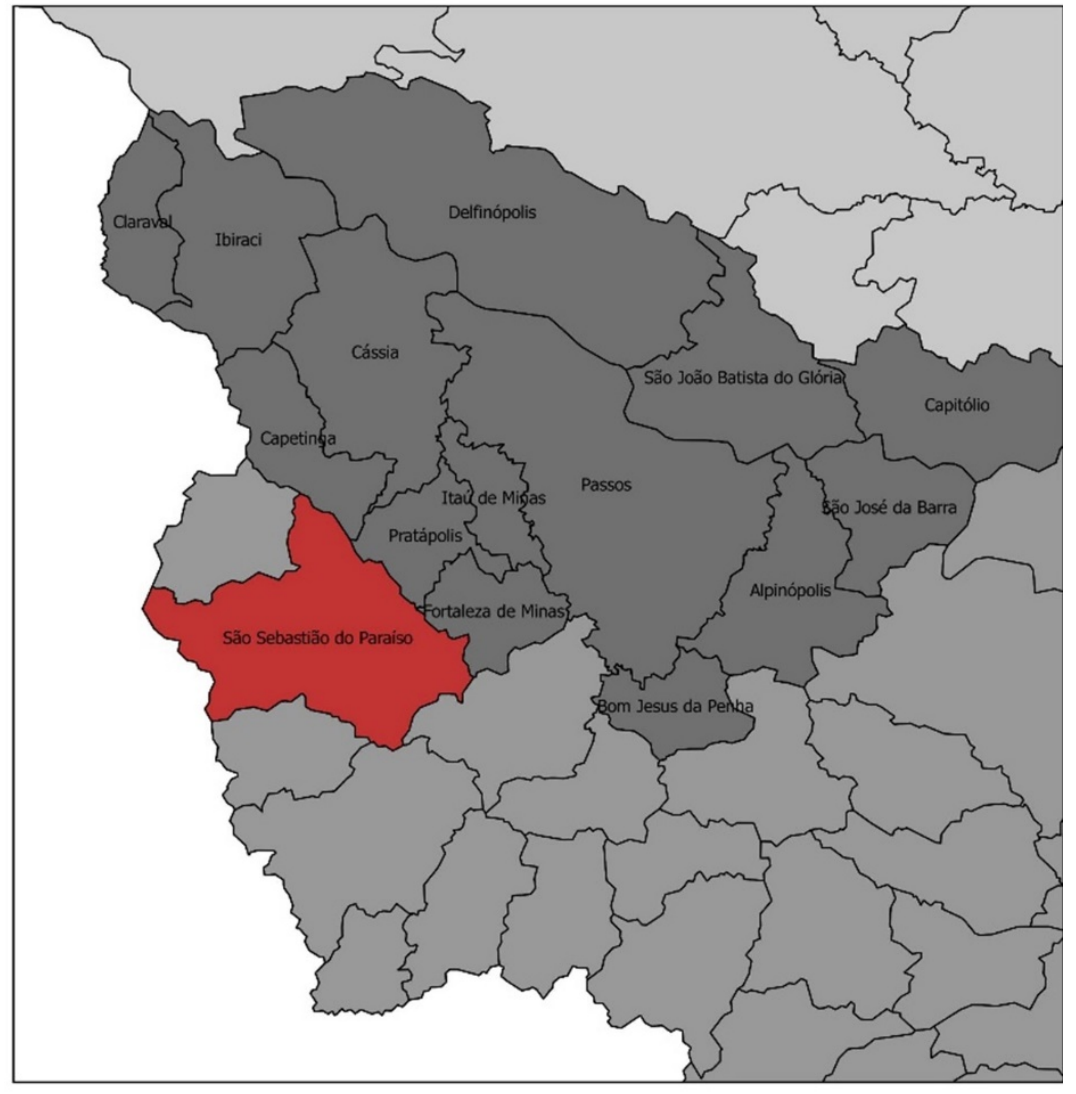

$10 \quad 0 \quad 10 \quad 20 \quad 30 \quad 40 \quad \mathbf{k m}$

ש Cartografia LIBORIO, M. P. (2015)

Figura 1 - Mapa de localização de São Sebastião do Paraíso, em Minas Gerais. Fonte: elaborada pelos autores com base em IBGE (2010).

Entre fevereiro de 2017 e janeiro de 2018, a arrecadação do IPTU em SSP somou R \$ 5,8 milhões, representeando 24,5\% da receita tributária total (São Sebastião do Paraíso, 2017). Dados obtidos no SICONFI (2018) mostram que essa arrecadação cresceu 35\% até o fechamento do ano de 2018, somando R\$ 7,8 milhões. 0 cálculo do IPTU em SSP é descrito na Lei Municipal (LM) no 1.773/89 (São Sebastião do Paraíso, 1989). Conforme LM no 2.888/01 (São Sebastião do Paraíso, 2001), as alíquotas aplicáveis são $0,8 \%$ para edificações e $3 \%$ para terrenos.

\section{Etapas de desenvolvimento da pesquisa}

O desenvolvimento da pesquisa se dividiu em três etapas: (i) compreensão do padrão espacial da oferta de bens-serviços públicos; (ii) criação da Variável de Síntese Bens-Serviços Públicos (VS-BSP); e (iii) formulação do instrumento (alíquota do imposto) de justiça social. A Figura 2 ilustra a finalidade e os procedimentos realizados em cada etapa da pesquisa. 


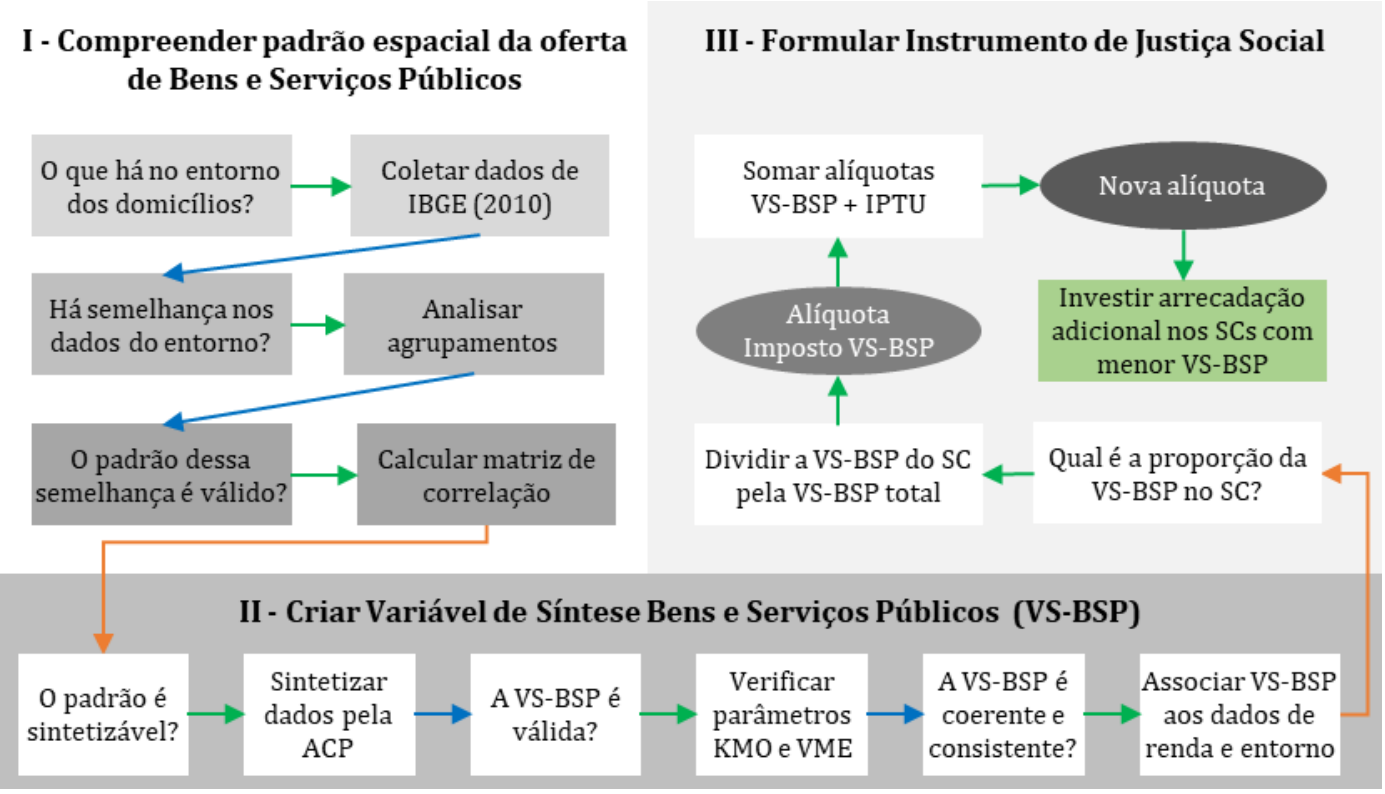

Figura 2 - Etapas de desenvolvimento da pesquisa. Fonte: elaborada pelos autores.

Na primeira etapa, buscou-se identificar e validar a presença de semelhanças ou padrões espaciais na oferta de bens-serviços públicos nos SCs de SSP. Para isso, realizaram-se, respectivamente, as análises de agrupamentos e de correlações. A análise de agrupamentos é uma técnica que possibilita a criação de grupos de indivíduos ou de características internamente semelhantes e externamente dissemelhantes (Alencar et al., 2013). Em virtude dessa possibilidade analítica, não é difícil encontrar pesquisas que aplicam a análise de agrupamentos na geografia. Por exemplo, é possível citar pesquisas na área da geografia ambiental (Roboredo et al., 2018), geografia regional (Fonseca \& Aguiar, 2019), geografia urbana (Fonseca et al., 2017), entre outras (Fante \& Sant'Anna, 2017). Na presente pesquisa, aplicou-se a análise de agrupamentos para responder se havia semelhança (padrão espacial) entre as 13 variáveis do entorno. As variáveis com dissemelhança menor do que 1,5 foram classificadas como: padrão espacial semelhante. Em seguida, validou-se estatisticamente o padrão espacial por meio da matriz de correlações das variáveis selecionadas. As variáveis com correlações moderadas $(0,5<R<0,7)$, fortes $(0,7<R<0,9)$ ou muito fortes $(R>0,9)$ (Hair et al., 2019) foram consideradas como padrão espacial válido. Na prática, as análises de agrupamentos e de correlação permitiram identificar quais variáveis descartar antes de iniciar a etapa de criação da VS-BSP.

Na segunda etapa, realizou-se a criação da VS-BSP por meio da ACP (Alencar et al., 2014) e verificou-se se o padrão espacial da oferta de bens-serviços públicos poderia ser sintetizável. Jolliffe (1972) explica que os resultados da ACP podem ser melhorados quando variáveis com características muito diferentes das demais são previamente descartadas. A análise de agrupamentos e a correlação são métodos eficientes para identificar as variáveis a serem descartadas na ACP, pois mostram o quanto as variáveis se diferenciam ou se parecem (Jolliffe, 1972). Em outras palavras, esses métodos permitem excluir variáveis com distribuição de dados destoante das demais variáveis, contribuindo para se encontrar um padrão espacial e alcançar melhorares resultados na APC e, consequentemente, na criação da variável de síntese. $\mathrm{O}$ uso da ACP para criar variáveis de síntese de natureza socioeconômica, estrutural e do meio físico é muito comum na geografia (ver Hummell et al., 2016; Carreço \& Castiglioni, 2018). Por meio da ACP, é possível representar muitas variáveis geográficas simultaneamente e ainda identificar quais são as mais importantes na representação. Para isso, analisam-se os pesos dos coeficientes de determinação de cada variável (Greco et al., 2019), os quais podem revelar, por exemplo, qual variável tem a maior influência na desproporcionalidade da carga tributária do IPTU (Fonseca et al., 2017). Ainda assim, como saber se a VS-BSP era válida? Para responder a essa pergunta, verificaram-se a Variância Média Extraída (VME) e a adequação da amostra (teste Kaiser-Meyer-Olkin-KMO). Hair et al. (2019) sugerem aceitar um modelo de ACP quando a VME é maior do que 60\% e o KMO é maior do que 0,5. 
Após validar os parâmetros estatístico, perguntou-se: a VS-BSP é coerente com a realidade? Para tanto, verificou-se se havia uma relação positiva entre a VS-BSP e as variáveis do entorno e o rendimento nominal mensal. Para isso, compararam-se os 10 SCs com menor incidência da VS-BSP aos 10 SCs com maior incidência da VS-BSP. Validada sua coerência, a VS-BSP e as variáveis selecionadas na análise de agrupamentos foram normalizadas, mapeadas e analisadas. A normalização é um mecanismo de transformação que converte as escalas de variáveis com grandezas diferentes para uma escala única, possibilitando sua comparação (Pedrycz et al., 2011, p. 108). Conforme os autores, essa normalização é obtida pela diferença entre o valor da variável observada e o valor mínimo da série de dados, dividida pela diferença entre o valor máximo e o valor mínimo da série de dados.

$\mathrm{Na}$ terceira etapa, buscou-se atribuir o ônus relativo aos benefícios produzidos pelos bens-serviços públicos. Ou seja, qual era a proporção da VS-BSP em cada SC? Qual era a alíquota referente ao VS-BSP? Para isso, calculou-se o percentual da VS-BSP do SC em relação à VS-BSP total. 0 resultado desse cálculo foi a alíquota da VS-BSP, a qual, por sua vez, foi somada à alíquota do IPTU. Por fim, a arrecadação adicional produzida pela nova alíquota era revertida em bens-serviços públicos em SCs com menor VS-BSP. A título de exemplo, arbitrou-se que essa arrecadação aumentava em $10 \%$ a oferta de bens-serviços públicos nos $10 \mathrm{SCs}$ com menor incidência da VS-BSP.

\section{Resultados e discussōes}

Os resultados da primeira etapa de desenvolvimento da pesquisa estão associados à definição e validação das variáveis que representavam a oferta de bens-serviços públicos e que possuíam o mesmo padrão espacial. A Figura 3 traz em destaque as variáveis com dissemelhança menor do que 1,5, bem como os coeficientes de correlação entre essas variáveis.

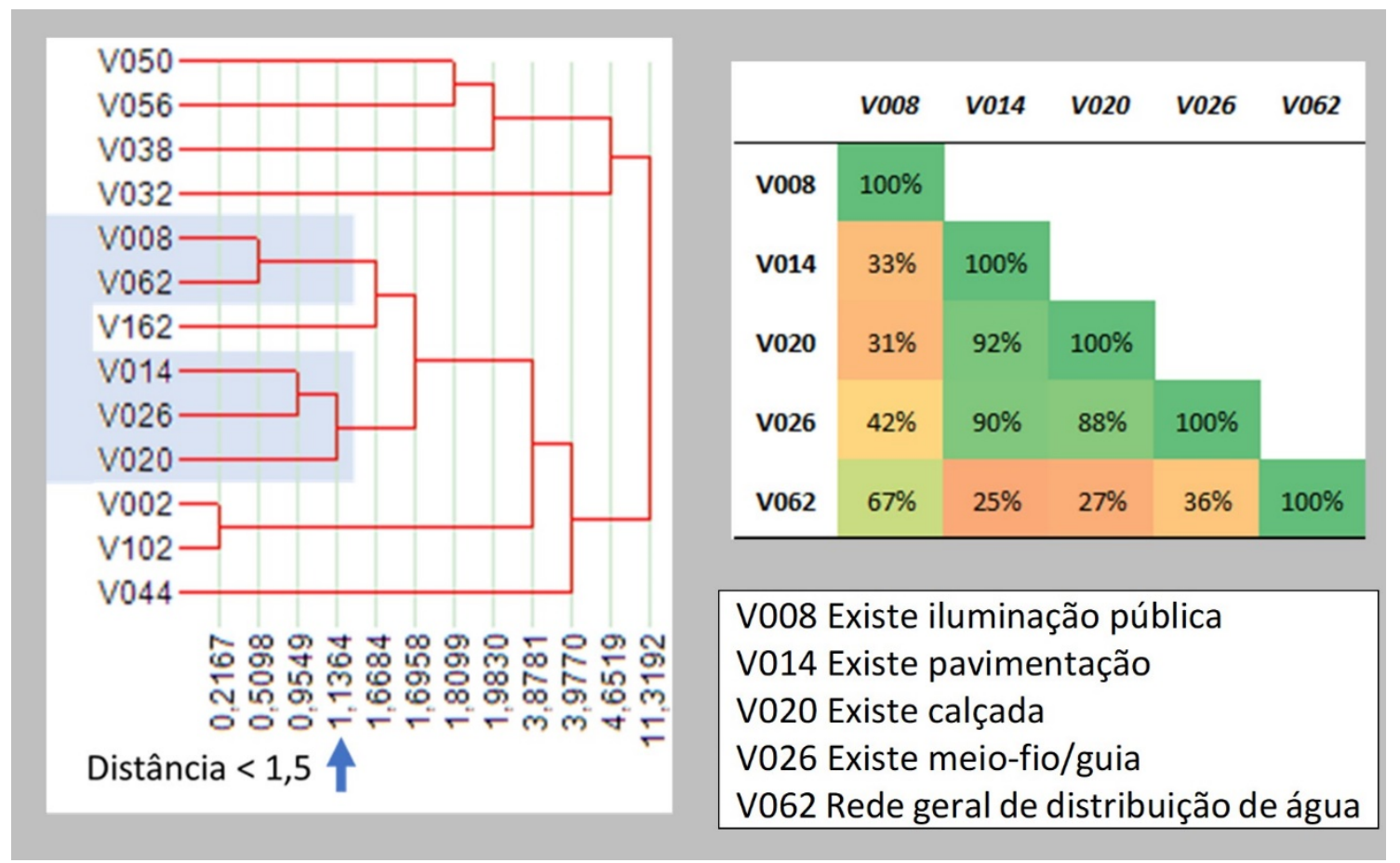

Figura 3 - Seleção/validação das variáveis - agrupamento hierárquico e matriz de correlações. Fonte: elaborada pelos autores.

Pela análise de agrupamentos hierárquicos, selecionaram-se para compor a VS-BSP cinco variáveis do entorno: V008 (iluminação pública), V014 (pavimentação), V020 (calçada), V026 (meio-fio/guia) e V062 (rede geral de distribuição de água). Pela matriz de correlação, observou-se um coeficiente de correlação 
moderada $(0,5<R<0,7)$ entre V008 e V062, ou seja, considerando os SCs de SSP, a iluminação pública estava moderadamente correlacionada à rede geral de distribuição de água. Entre V014, V020 e V026, percebeu-se uma correlação muito forte $(R>0,9)$. Isso significa que a pavimentação estava muito fortemente correlacionada à presença de calçada e meio-fio/guia. Por fim, constatou-se um coeficiente de correlação forte entre V026 e V062, isto é, a presença de calçada nos SCs urbanos de SSP estava fortemente correlacionada à presença de meio-fio.

Esses resultados indicam que as variáveis selecionadas pelo agrupamento hierárquico são pelo menos moderadamente correlacionadas e, portanto, há um padrão espacial na distribuição desses bens-serviços públicos em SSP. Isso significa, por exemplo, que áreas menos pavimentadas também são menos calçadas. A Tabela 1 detalha as variáveis que possuem o mesmo padrão espacial e, por isso, compõem a VS-BSP.

Tabela 1 - Variáveis que possuem o mesmo padrão espacial e compõem a Variável de Síntese Bens-Serviços Públicos (VS-BSP)

\begin{tabular}{|c|c|}
\hline Variável & Descrição \\
\hline Calçada & $\begin{array}{c}\text { Existia caminho calçado ou pavimentado, destinado à circulação de } \\
\text { pedestres, quase sempre mais alto que a parte do logradouro em que } \\
\text { trafegavam os veículos. }\end{array}$ \\
\hline lluminação pública & Existia pelo menos um ponto fixo (poste) de iluminação pública. \\
\hline Meio-fio/guia & Existia borda ao longo do logradouro. \\
\hline Pavimentação & $\begin{array}{l}\text { Existia cobertura da via pública com asfalto, cimento, paralelepípedos, pedras } \\
\text { etc. }\end{array}$ \\
\hline Rede geral de distrib. de água & $\begin{array}{c}\text { O domicílio ou o terreno, ou a propriedade onde estava localizado, estavam } \\
\text { ligados a uma rede geral de distribuição de água. }\end{array}$ \\
\hline
\end{tabular}

Fonte: adaptada pelos autores a partir de informações do IBGE (2010).

Os resultados da segunda etapa de desenvolvimento da pesquisa estão associados à criação da VS-BSP por meio da ACP. A VS-BSP sintetizou cinco variáveis e representou o padrão espacial da oferta de bens-serviços públicos dos SCs urbanos de SSP. A VME das cinco variáveis é ilustrada na Figura 4 e sinaliza o poder de explicação da VS-BSP.

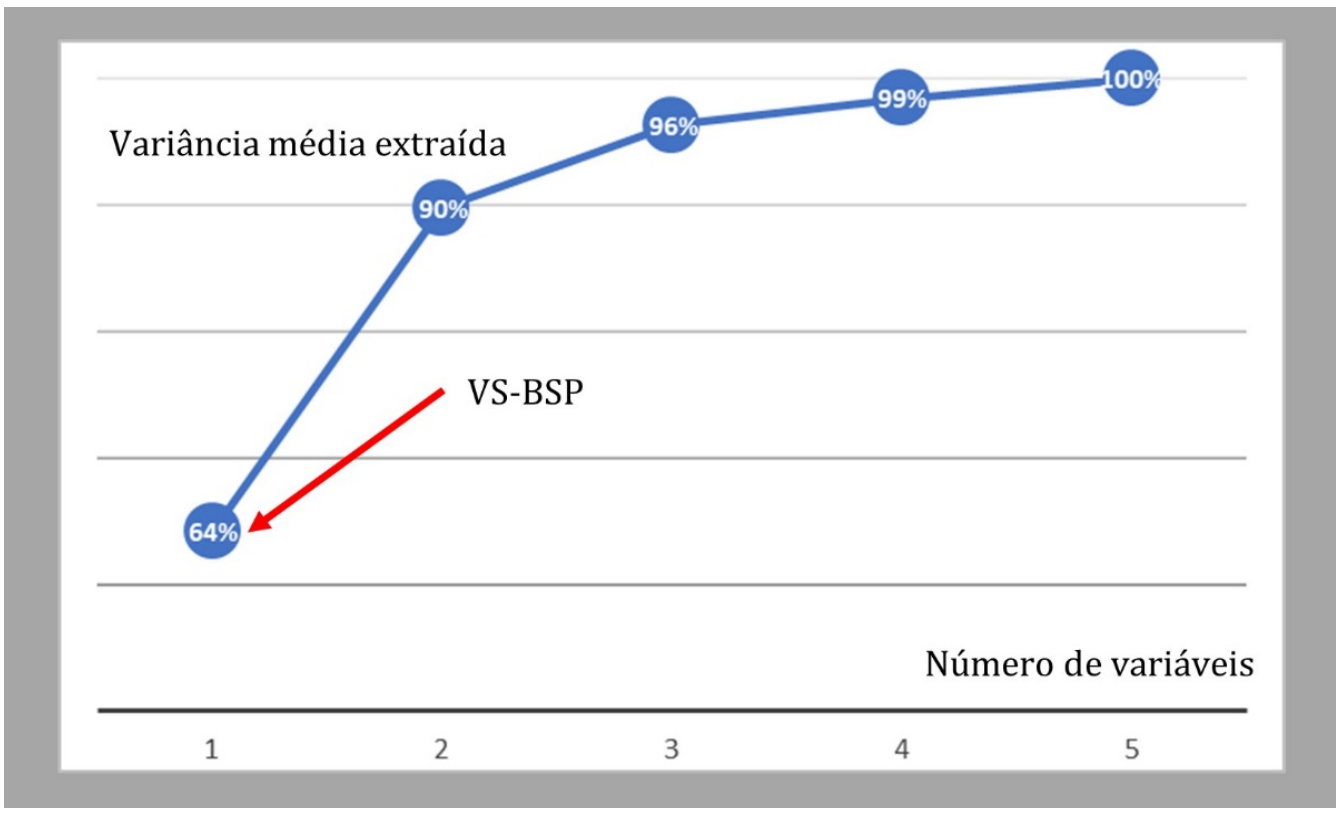

Figura 4 - Variância Média Extraída (VME) das variáveis selecionadas para compor a Variável de Síntese Bens-Serviços Públicos (VS-BSP). Fonte: elaborada pelos autores. 
A VME da VS-BSP ficou acima do mínimo aceitável de 50\%, explicando 64\% do padrão espacial das cinco variáveis de bens-serviços públicos. A importância relativa das variáveis foram: V026 = 28\%; V014 = 26\%; V020 = 26\%; V008 = 11\%; e V062 = 9\%. Esses resultados indicam que $80 \%$ da VS-BSP era composta pela presença de meio-fio/guia, pavimentação e calçada. Por sua vez, as variáveis iluminação pública e rede geral de distribuição de água representaram juntas $20 \%$ da VS-BSP. Esses resultados podem ser considerados estatisticamente válidos, pois a medida de adequação da amostra, teste KMO, foi de 0,75 e superou o valor crítico de $50 \%$. Por sua vez, a coerência da VS-BSP é demonstrada na Figura 5, que evidencia uma maior proporção de bens-serviços públicos nos SCs com maior incidência da VS-BSP.

V050 Esgoto a céu aberto
V056 Lixo acumulado
V038 Rampa para cadeirante
V032 Bueiro/boca de lobo
V044 Arborização
V162 Lixo coletado
V102 Rede geral esgoto
V002 Identificação logradouro
V020 Calçada
V014 Pavimentação
V026 Meio-fio/guia
V008 Iluminação pública
V062 Rede distribuição água

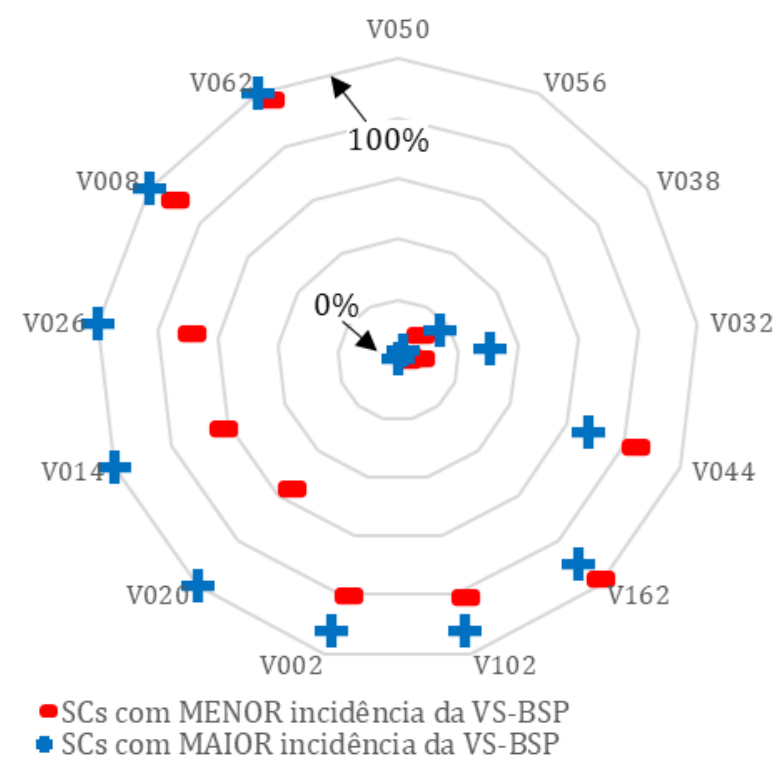

Figura 5 - Proporção de bens-serviços públicos em Setores Censitários (SCs) de São Sebastião do Paraíso (SSP), em Minas Gerais, com maior e menor presença da Variável de Síntese Bens-Serviços Públicos (VS-BSP).

Fonte: elaborada pelos autores.

Observa-se nesse gráfico que a presença das variáveis de bens-serviços públicos nos SCs com maior incidência da VS-BSP foi, em média, $12 \%$ maior do que em SCs com menor incidência da VS-BSP. Destaca-se que as variáveis V014, V020, V026 e V032 apresentaram diferenças superiores a 20\%, ou seja, SCs com maior incidência da VS-BSP possuíam uma presença 35\% maior em pavimentação, $43 \%$ maior em calçadas, $28 \%$ maior em meio-fio/guia e $26 \%$ em bueiro/boca de lobo. Entre as diferenças inferiores a 10\% estavam as variáveis V008 e V062. Nesses casos, a diferença da presença de iluminação pública e rede geral de distribuição de água entre SCs com maior e menor incidência da VS-BSP foi de 7\% e 3\%, respectivamente. Por sua vez, a variável V044 destacou-se entre as diferenças negativas. No caso de SSP, SCs com menor incidência da VS-BSP possuíram maior presença de arborização. Ainda assim, em 70\% dos casos (13 variáveis), a presença de bens-serviços públicos foi maior em SCs com maior incidência da VS-BSP. Além disso, o rendimento nominal mensal de domicílios em SCs com maior incidência da VS-BSP chegava a $\mathrm{R} \$ 3.370,32$. Esse rendimento foi $\mathrm{R} \$ 2.032,55$ (ou 151\%) maior do que o rendimento nominal mensal por domicílio em SCs com menor incidência da VS-BSP (R $1.337,77)$. Isso significa que SCs com maior incidência da VS-BSP concentravam mais bens-serviços públicos e mais domicílios de maior renda. Considerando a relação direta entre a proporção de bens-serviços públicos e o rendimento nominal mensal com os valores da VS-BSP (0,59 e -2,49, respectivamente), conclui-se que os achados se alinham ao que se expõe na literatura da desigualdade urbana revisada (Oates, 1969, 2001; Lopes \& Santos, 2010; Libório et al., 2018; Fonseca \& Aguiar, 2019; Carvalho et al., 2019). A Figura 6 oferece uma visão geográfica desses achados, ilustrando o padrão espacial da distribuição/concentração da oferta específica (cinco variáveis) e conjunta (VS-BSP) de bens-serviços públicos nos SCs urbanos de SSP. 


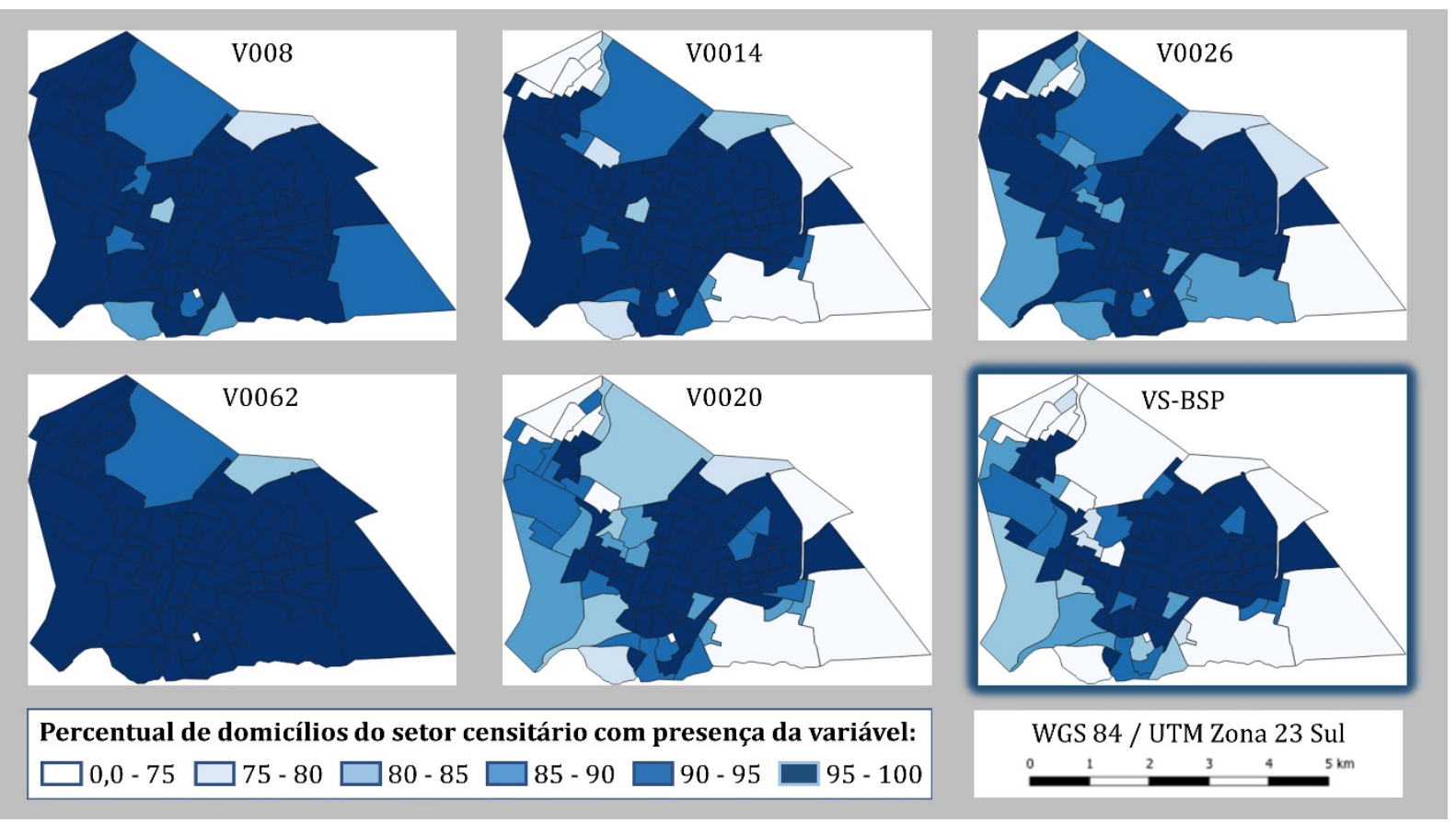

Figura 6 - Mapa dos bens-serviços públicos nos Setores Censitários (SCs) urbanos de São Sebastião do Paraíso (SSP), em Minas Gerais. Fonte: elaborada pelos autores.

Considerando o princípio da alocação proporcional de recursos (Pedrycz et al., 2011), estima-se que 4,63\% dos bens-serviços públicos sirvam a domićlios presentes nos 10 SCs com menor incidência da VS-BSP. Por sua vez, estima-se que $11,78 \%$ dos bens-serviços públicos sirvam a domićlios presentes nos SCs com maior incidência da VS-BSP, ou seja, os 2.290 domicílios (12\% do total) menos favorecidos possuíam 2,54 vezes menos bens-serviços públicos do que os 1.860 domicílios ( $10 \%$ do total) mais favorecidos. Logo, não se pode negar que é preciso considerar a presença dos bens-serviços públicos e os benefícios produzidos por eles (valorização dos imóveis e bem-estar) na formulação do IPTU, exemplificada na Figura 7.

\begin{tabular}{ccc}
316470410000002 & Identificação do SC & 316470405000016 \\
0,28 & VS-BSP do SC & 1,00 \\
84,9 & VS-BSP total & 84,9 \\
$0,28 / 84,9=0,34 \%$ & Alíquota do VS-BSP & $1 / 84,9=1,18 \%$ \\
$0,8 \%$ & Alíquota do IPTU & $0,8 \%$ \\
\hline $26.34 \%+0,8 \%$ & Nova alíquota & $1,18 \%+0,8 \%$ \\
\hline $118.560,00$ & Retorno em investimentos & 0,00 \\
\hline
\end{tabular}

SC com menor incidência da VS-BSP - SC com maior incidência da VS-BSP

Figura 7 - Formulação da alíquota considerando a Variável de Síntese Bens-Serviços Públicos (VS-BSP) em dois Setores Censitários (SCS) selecionados aleatoriamente. Fonte: elaborada pelos autores. 
Considerando, por exemplo, as alíquotas da VS-BSP dos 10 SCs com menor e maior incidência de bensserviços públicos e a alíquota do IPTU, há uma alíquota adicional de 0,46\% e 1,18\%, respectivamente. Isso significa um aumento médio no IPTU de 46\% (entre 0\% e 95\%) para SCs menos favorecidos e de $147 \%$ para SCs mais favorecidos. Somadas as alíquotas da VS-BSP e do IPTU, tem-se então uma nova alíquota, a qual está entre $0,0 \%$ e $0,76 \%$ para domicílios em SCs com menor incidência da VS-BSP. Para domicílios em SCs com maior incidência da VS-BSP, a alíquota é de 1,98\%.

Com essa nova alíquota, estima-se uma arrecadação adicional de $100 \%$, ou seja, uma arrecadação adicional de $\mathrm{R} \$ 7,8$ milhões/ano, que seria então investida em bens-serviços públicos (iluminação pública, pavimentação, calçada, meio-fio/guia e rede geral de distribuição de água) em SCs com menor incidência da VS-BSP. A Tabela 2 traz uma estimativa do impacto na redução das desigualdades entre SCs, simulando uma situação em que o investimento de toda a arrecadação adicional melhora em $10 \%$ a presença dos cinco bens-serviços públicos nos 10 SCs com menor incidência da VS-BSP.

Tabela 2 - Estimativa de redução das desigualdades na distribuição de bens-serviços públicos entre Setores Censitários (SCs) com maior e menor incidência da Variável de Síntese Bens-Serviços Públicos (VS-BSP)

\begin{tabular}{cccc}
\hline Bens e serviços públicos & $\begin{array}{c}\text { Desigualdade no } \\
\text { momento inicial }\end{array}$ & $\begin{array}{c}\text { Desigualdade após } \\
\text { investimento }\end{array}$ & $\begin{array}{c}\text { Redução da } \\
\text { desigualdade }\end{array}$ \\
\hline V008 lluminação pública & $7 \%$ & $2 \%$ & $-72 \%$ \\
V014 Pavimentação & $35 \%$ & $25 \%$ & $-28 \%$ \\
V020 Calçada & $43 \%$ & $33 \%$ & $-23 \%$ \\
V026 Meio-fio/guia & $28 \%$ & $18 \%$ & $-35 \%$ \\
V062 Rede geral dist. água & $3 \%$ & $1 \%$ & $-75 \%$ \\
Média das cinco variáveis & $23 \%$ & $16 \%$ & $-47 \%$ \\
Variável bem público & 3,08 & 2,20 & $-29 \%$ \\
\hline
\end{tabular}

Fonte: elaborada pelos autores.

Esses resultados sugerem que, ao se atribuir o ônus equivalente aos ganhos obtidos dos bens-serviços públicos, extraem-se recursos adicionais de áreas mais favorecidas que podem ser investidos em infraestrutura urbana (Carvalho, 2014). Essa estratégia, em teoria, pode contribuir para reduzir o problema da desigualdade na distribuição de bens-serviços públicos (Cruz, 2012), ou seja, reduzir a concentração de bens-serviços públicos em regiões mais favorecidas (Ferreira et al., 2019; Mendonça et al., 2019). Isso porque a VS-BSP permite redistribuir o ônus equivalente aos ganhos obtidos de bens-serviços públicos em SSP dos atuais 0,08\% para 0,0317\% em áreas menos favorecidas e para 0,0942\% em áreas mais favorecidas. Além disso, a alíquota adicional extraída majoritariamente das áreas mais favorecidas aumenta a arrecadação em $\mathrm{R} \$ 7,8$ milhões/ano, a qual, se revertida em bens-serviços públicos, pode reduzir em $47 \%$ a desigualdade entre os SCs de SSP. Essa redução significa, em última análise, uma distribuição $29 \%$ menos desigual da VS-BSP e uma melhor distribuição dos benefícios produzidos pelos bens-serviços públicos.

Entretanto, atribuir qualquer ônus às famílias de áreas menos favorecidas pode reforçar a relativa regressividade do IPTU. Ainda que a alíquota proposta nesta pesquisa se alinhe ao princípio da progressividade tributária (Sabbag, 2019), qualquer aumento do IPTU representa uma parcela significativa dos gastos das famílias mais pobres (Slack \& Bird, 2015). Para evitar tal regressividade, sugere-se ampliar iniciativas como a LM no 3.134/2004, a qual concede isenção do pagamento do IPTU a proprietários aposentados com comprovada carência socioeconômica e financeira e renda inferior a um salário mínimo mensal (São Sebastião do Paraíso, 2004). Outra possibilidade é a alteração da fórmula da alíquota da VS-BSP que possa manter ou eliminar a alíquota do IPTU.

Quanto aos resultados, eles trazem evidências empíricas de que há uma concentração de investimentos em bens-serviços públicos em áreas mais favorecidas (Oates, 1969, 2001; Lopes \& Santos, 2010). Essas evidências também reforçam a ideia de que há um padrão espacial de desigualdade (Furtado; 2011; Netto et al., 2012; Cruz, 2012), o qual existe por causa das correlações moderadas, fortes e muito fortes entre as variáveis que representam bens-serviços públicos (calçada, iluminação pública, meio-fio/guia, pavimentação, rede geral de distribuição de água) e também em razão da relação direta e 
positiva entre a VS-BSP e o rendimento nominal mensal dos domicílios. Por outro lado, não se confirma que a arborização urbana é mais encontrada em áreas mais favorecidas (Silva et al., 2016; Ferreira et al., 2019). Contudo, é preciso lembrar que Silva etal. (2016) e Ferreira etal. (2019) analisaram, respectivamente, cidades 3,2 e 7,5 vezes maiores do que SSP. Além disso, é importante destacar que os resultados alcançados (seleção das variáveis, correlações e VS-BSP) são particulares à cidade de SSP-MG, por isso a generalização do instrumento proposto se limita à sua metodologia.

\section{Conclusões}

Esta pesquisa se soma a outros trabalhos (Smolka, 1991) que discutem propostas para potencializar os tributos como instrumentos efetivos de justiça social. No presente caso, trata-se de aumentar a progressividade do IPTU com base nos benefícios produzidos pela presença de bens-serviços públicos, contribuindo para o enfrentamento dos vários desafios econômicos, sociais e políticos que reforçam desigualdades. 0 desafio é econômico porque municípios tem na arrecadação do IPTU uma das principais fontes de recursos (Longo \& Lima, 1982; Rezende, 2010), e, ao mesmo tempo, restrições administrativas, jurídicas e financeiras para melhorar essa arrecadação (Carvalho, 2014). 0 desafio também é social porque reformas para aumentar a arrecadação do IPTU podem reforçar desigualdades, uma vez que se observa uma relativa regressividade na cobrança desse imposto (Cesare, 2012; Slack \& Bird, 2015). Ainda, o desafio é político porque propostas de reformas no IPTU são impopulares, sendo associadas às "revoltas do contribuinte" (Dornfest, 2005), trazendo, portanto, custos políticos.

Argumenta-se que, para superar esses desafios, utilize-se do princípio do benefício (Mankiw, 2016), da progressividade tributária (Sabbag, 2019) e da alocação de recursos (Pedrycz etal., 2011). Em conjunto, esses princípios sustentam a proposta de se alocar a cada cidadão o ônus proporcional aos ganhos dos bens-serviços públicos. Para isso, considera-se os bens-serviços públicos divisíveis para fins tributários (Rezende, 2010). Isso significa manter o princípio da acessibilidade universal e, ao mesmo tempo, potencializar a função de instrumento de justiça social do IPTU.

Assim, considerando-se a proporcionalidade do benefício produzido pelos bens-serviços públicos, por exemplo, a valorização dos imóveis e do bem-estar (Mark \& Goldberg, 1986; Mendonça et al., 2019), propõe-se atribuir um imposto adicional maior às áreas que concentram maior renda e maior oferta de bens-serviços públicos (Fonseca et al., 2017; Fonseca \& Aguiar, 2019).

Conclui-se nesta pesquisa que, além de evidências empíricas que confirmam as características da desigualdade urbana, o uso de novos modelos e métodos de análise espacial podem ser úteis no avanço das discussões sobre políticas objetivas de redução de desigualdades. Nesse caso, trata-se de contribuir para distribuir a carga tributária do IPTU (Fonseca et al., 2017) de forma coerente com a oferta bens-serviços públicos. Ao fazê-la, estima-se que seja possível reduzir em $47 \%$ as diferenças na distribuição dos benefícios produzidos pelos bens-serviços públicos. Seriam esses resultados suficientes para uma ação mais concreta? 0 instrumento proposto é viável?

Independentemente dessas respostas, sugere-se aprofundar e expandir a pesquisa, incluindo outros dados (praças, museus, parques etc.) ou replicando a metodologia para outras cidades. Sugere-se ainda que se comparem resultados, analisando-se características das cidades, para se destacar particularidades e semelhanças das desigualdades. Por fim, não custa lembrar que o instrumento proposto possui limitações. Os dados do censo são coletados decenalmente. A VS-BSP tende a variar entre as diferentes unidades de análise em razão do uso da ACP. A importância relativa de cada variável do entorno na VS-BSP não foi explorada na estimativa de redução das desigualdades. Por fim, essas estimativas devem ser aprofundadas, pois se fundamentam na premissa de que a arrecadação adicional aumenta em $10 \%$ a oferta de bens-serviços públicos nos 10 SCs menos favorecidos. Considerando-se a relevância dessa limitação, coloca-se como agenda de pesquisa futura levantar os custos de investimento nos cinco bens-serviços públicos presentes na VS-BSP. Mais do que isso, com base na relação entre os custos levantados e os recursos adicionais arrecadados, calcular o quanto se pode aumentar a oferta de bens-serviços públicos nos $10 \mathrm{SCs}$ menos favorecidos, bem como 
verificar se a redução na desigualdade urbana seria maior ou menor do que os $47 \%$ estimados nesta pesquisa. Em que se pese o fato de que muitas perguntas ainda permanecem em aberto, esta pesquisa traz para a literatura um exemplo de como utilizar a tributação enquanto instrumento de justiça social. Por mais que tal instrumento esteja distante de se concretizar, coloca-se aqui uma metodologia que contribui para que pesquisadores avancem nesse sentido.

\section{Agradecimentos}

A presente pesquisa foi realizada com apoio da: (i) Coordenação de Aperfeiçoamento de Pessoal de Nível Superior (CAPES), Código de Financiamento 001; (ii) Conselho Nacional de Desenvolvimento Cientifico e Tecnológico (CNPq), Grant 311032/2016-8; e (iii) Fundação de Amparo à Pesquisa do Estado de Minas Gerais (Fapemig), APQ-02891-14.

\section{Referências}

Alencar, B. J., Barroso, L. C., \& Abreu, J. F. (2013). Análise multivariada de dados no tratamento da informação espacial: uma abordagem com análise de agrupamentos. Sistemas. Cibernética e Informática, 10(2), 6-12.

Alencar, B. J., Barroso, L. C., \& Abreu, J. F. (2014). Análise de Componentes Principais Aplicada ao Tratamento de Dados Espaciais. In Anais da $13^{\circ}$ Conferência Ibero-Americana em Sistemas, Cibernética e Informática - CISCI (Vol. 1, pp. 20-25). Orlando-Florida-EUA: International Institute of Informatics and Systemics.

Bahl, R., \& Bird, R. M. (2018). Fiscal decentralization and local finance in developing countries. Cheltenham: Edward Elgar Publishing. http://dx.doi.org/10.4337/9781786435309.

Berry, C. (2001). Land use regulation and residential segregation: does zoning matter? American Law and Economics Review, 3(2), 251-274. http://dx.doi.org/10.1093/aler/3.2.251.

Brasil. (1966). Código Tributário Nacional. Brasília: Senado Federal.

Brasil. (2008). Estatuto da Cidade (3. ed., 102 p.). Brasília: Senado Federal, Subsecretaria de Edições Técnicas. Recuperado em 21 de janeiro de 2020, de https://e-law.net.br/fsa/2018/civil-iii/elaw-estatuto-da-cidade.pdf

Carlos, A. F. A. (2011). Diferenciação socioespacial. Cidades, 4(6), 45-60.

Carrara, A. A. (2006). Mineração, Produção Rural e Espaços Urbanos em Minas Gerais: 1808-1835. In Anais do XII Seminário sobre a Economia Mineira. Belo Horizonte: CEDEPLAR, UFMG.

Carreço, H., \& Castiglioni, A. H. (2018). Análise da vulnerabilidade socioambiental no município de Vitória-ES, com o apoio de um SIG livre. Caderno de Geografia, 28(55), 1076-1102. http://dx.doi.org/10.5752/P.23182962.2018v28n55p1076-1102.

Carvalho, C., Fridman, F., \& Strauch, J. (2019). Desigualdade, escala e políticas públicas: uma análise espacial dos equipamentos públicos nas favelas cariocas. Urbe. Revista Brasileira de Gestão Urbana, 11, 1-12.

http://dx.doi.org/10.1590/2175-3369.011.002.ao04.

Carvalho, J. (2014). Property tax performance in São Paulo. Journal of Property Tax Assessment \& Administration, 11(2), 63-89.

Cesare, C. M. (2012). Improving the performance of the property tax in Latin America. Cambridge: Lincoln Institute of Land Policy.

Cruz, D. A. M. O. (2012). As faces do planejamento urbano. Revista Pegada, 12(2), 81-94.

Dornfest, A. S. (2005). Effects of taxable value increase limits fables and fallacies. Journal of Property Tax Assessment \& Administration, 2(4), 5-15. 
Elinder, M., \& Persson, L. (2017). House price responses to a national property tax reform. Journal of Economic Behavior \& Organization, 144, 18-39. http://dx.doi.org/10.1016/j.jebo.2017.09.017.

Fante, K. P., \& Sant'Anna, J. L., No. (2017). Mudanças nos padrões da temperatura do Estado de São Paulo/Brasil nos últimos 50 anos. Revista do Departamento de Geografia, 33, 12-23.

http://dx.doi.org/10.11606/rdg.v33i0.125767.

Farias, F. O., Bargos, D. C., \& Matias, L. F. (2016). Aplicação de geotecnologias no estudo da relação entre a valorização da terra urbana e a presença de áreas verdes na cidade de Paulínia (SP). Revista Brasileira de Cartografia, 68(2), 275-287.

Fernandes, E. (2011). Implementing the urban reform agenda in Brazil: possibilities, challenges, and lessons. Urban Forum, 22(3), 299-314. http://dx.doi.org/10.1007/s12132-011-9124-y.

Fernandes, E., \& Alfonsin, B. (2014). Direito à moradia adequada: o que é, para quem serve, como defender e efetivar. Belo Horizonte: Ed. Fórum.

Ferreira, C. C. M., Monteiro, A., \& Paula, I. F. M. (2019). Áreas verdes e desigualdades sociais em um município de médio porte no Brasil. Caderno de Geografia, 29(56), 209-231. http://dx.doi.org/10.5752/P.23182962.2019v29n56p221.

Fonseca, D. F., Lobo, C., \& Garcia, R. A. (2017). Imposto predial e territorial urbano: uma metodologia de ajuste tributário para Belo Horizonte/MG. Urbe. Revista Brasileira de Gestão Urbana, 9(3), 513-526.

http://dx.doi.org/10.1590/2175-3369.009.003.ao10.

Fonseca, S. F., \& Aguiar, H. H. (2019). Identificação de Cluster de Concentração de Renda e Dependência Demográfica nos Vales do Jequitinhonha e Mucuri. Raega-O Espaço Geográfico em Análise, 46(1), 132-144. http://dx.doi.org/10.5380/raega.v46i1.57150.

Furtado, B. A. (2011). Neighbourhoods in urban economics: incorporating cognitively perceived urban space in economic models. Urban Studies (Edinburgh, Scotland), 48(13), 2827-2847.

http://dx.doi.org/10.1177/0042098010391288.

Greco, S., Ishizaka, A., Tasiou, M., \& Torrisi, G. (2019). On the methodological framework of composite indices: a review of the issues of weighting, aggregation, and robustness. Social Indicators Research, 141(1), 61-94.

http://dx.doi.org/10.1007/s11205-017-1832-9.

Hair, J. F., Black, W. C., Babin, B. J., Anderson, R. E., \& Tatham, R. L. (2019). Multivariate Data Analysis (8th ed.). U.K.: Cengage.

Hilber, C. A. L. (2017). The economic implications of house price capitalization: a synthesis. Real Estate Economics, 45(2), 301-339. http://dx.doi.org/10.1111/1540-6229.12129.

Hummell, B. M. L., Cutter, S. L., \& Emrich, C. T. (2016). Social vulnerability to natural hazards in Brazil. International Journal of Disaster Risk Science, 7(2), 111-122. http://dx.doi.org/10.1007/s13753-016-0090-9.

Instituto Brasileiro de Geografia e Estatistica -IBGE. (2010). Censo Demográfico 2010. Recuperado em 23 de julho de 2019, de https://censo2010.ibge.gov.br

Jolliffe, I. T. (1972). Discarding variables in a principal component analysis. I: artificial data. Journal of the Royal Statistical Society. Series C, Applied Statistics, 21(2), 160-173.

Leven, C. L. (1976). Neighborhood change: lessons in the dynamics of urban decay. Westport: Praeger Publishers.

Libório, M., Martinuci, O., Bernardes, P., \& Ekel, P. (2018). Medidas e escalas de desigualdade de renda em perspectiva. GOT. Revista de Geografia e Ordenamento do Território, 15, 287-314.

http://dx.doi.org/10.17127/got/2018.15.012.

Longo, C. A., \& Lima, J. C. D. (1982). The IPTU as a source of funds at the municipal level-efficiency and equity aspects. Revista Brasileira de Economia, 36(1), 85-102.

Lopes, W. M., Jr., \& Santos, R. C. B. (2010). Reprodução do espaço urbano e a discussão de novas centralidades. Raega-O Espaço Geográfico em Análise, 19, 107-123. http://dx.doi.org/10.5380/raega.v19i0.14827. 
Lynch, A. K., \& Rasmussen, D. W. (2004). Proximity, neighbourhood and the efficacy of exclusion. Urban Studies (Edinburgh, Scotland), 41(2), 285-298. http://dx.doi.org/10.1080/0042098032000165253.

Maas, L. W. D., Faria, E. O., \& Fernandes, J. L. C. (2019). Segregação socioespacial e oferta de serviços de saúde na Região Metropolitana de Belo Horizonte em 2010. Cadernos Metrópole, 21(45), 597-618.

http://dx.doi.org/10.1590/2236-9996.2019-4511.

Mankiw, N. G. (2016). Economics-microeconomics-principles of microeconomics. Boston: Cengage Learning.

Mark, J. H., \& Goldberg, M. A. (1986). A study of the impacts of zoning on housing values over time. Journal of Urban Economics, 20(3), 257-273. http://dx.doi.org/10.1016/0094-1190(86)90019-7.

Mendonça, J. G., Andrade, L. T., \& Diniz, A. M. A. (2019). Hypersegregation of the Brazilian metropolitan elites in the 2000s: interpretations based on the Belo Horizonte Metropolitan Region. Cadernos Metrópole, 21(44), 29-53. http://dx.doi.org/10.1590/2236-9996.2019-4402.

Netto, V. M., Vargas, J. C., \& Saboya, R. T. (2012). (Buscando) os efeitos sociais da morfologia arquitetônica. Urbe. Revista Brasileira de Gestão Urbana, 4(2), 261-282. http://dx.doi.org/10.7213/urbe.7400.

Oates, W. E. (1969). The effects of property taxes and local public spending on property values: an empirical study of tax capitalization and the TIEBOUT, hypothesis. Journal of Political Economy, 77(6), 957-971. http://dx.doi.org/10.1086/259584.

Oates, W. E. (2001). Property taxation and local government finance: an overview and some reflections. In W. E. Oates (Ed.), Property taxation and local government finance (pp. 21-32.). Cambridge, MA: Lincoln Institute of Land Policy.

Pedrycz, W., Ekel, P., \& Parreiras, R. (2011). Fuzzy multicriteria decision-making: models, methods and applications. Hoboken: John Wiley \& Sons.

Rezende, F. (2010). Finanças Públicas (2. ed.). São Paulo: Editora Atlas.

Roboredo, D., Bergamasco, S. M. P. P., Ara, A., Gervázio, W., \& Domingues, T. R. (2018). Clusterização de sistemas de manejos e a construção de indicadores de sustentabilidade utilizando a metodologia MESMIS no território Portal da Amazônia. Raega-O Espaço Geográfico em Análise, 43, 23-42. http://dx.doi.org/10.5380/raega.v43i0.48787.

Sabbag, E. M. (2019). Manual de direito tributário (11. ed.). São Paulo: Saraiva Educação, SA.

Sandroni, P. (2010). Captura de mais valias urbanas em São Paulo através do binômio solo criado/outorga onerosa: análise do impacto do coeficiente de aproveitamento único como instrumento do plano diretor de 2002. Relatório 202010. São Paulo: FGV - EAESP.

São Sebastião do Paraíso. (1989). Lei Municipal n.o 1.773, de 29/12/1989. Altera o código tributário municipal. São Sebastião do Paraíso: Diário Executivo. Recuperado em 10 de fevereiro de 2020, de http://www.ssparaiso.mg.gov.br/storage/downloads/c_digo_tribut_rio_municipal_lei_municipal_1773_89.pdf

São Sebastião do Paraíso. Prefeitura Municipal. (2001, 10 de dezembro). Lei Municipal Complementar n.․o 2.888, de 10/12/2001. Projeto de Lei Complementar no 3.049. Dispõe sobre alterações do código tributário do município, lei municipal no 1.773/89, Quanto a cobrança do iptu dos imóveis na área urbana do município e do ISSQN, e dá outras providências. São Sebastião do Paraíso: Diário Executivo. Recuperado em 23 de julho de 2019, de http://www.camarassparaiso.mg.gov.br/docs/Lei/LEI2888.pdf

São Sebastião do Paraíso. (2004). Lei Municipal n.o 3134, de 13/10/2004. Projeto de Lei no 3329, de 07/10/2004. Estabelece benefício fiscal aos aposentados residentes no município, que comprovarem carência socio-econômica e financeira e dá outras providencias. São Sebastião do Paraíso: Diário Executivo. Recuperado em 10 de fevereiro de 2020, de http://www.camarassparaiso.mg.gov.br/docs/Lei/LEI3134.pdf

São Sebastião do Paraíso. Sistema de Informações Fiscais. (2017). Relatório resumido da execução orçamentária de 2017. São Sebastião do Paraíso: SIF. Recuperado em 17 de julho de 2019, de http://sif.netgov.com.br/relatorios/3164704/2018/3164704_0_STN_Anexo_III_01_01012018.pdf?1523662963 
Silva, J. K., Libório, M. P., \& Laudares, S. (2016). Geovisualização da Arborização Viária Patrimoniada da Zona Central de Sete Lagoas-MG. Revista da Sociedade Brasileira de Arborização Urbana, 11(3), 56-72.

http://dx.doi.org/10.5380/revsbau.v11i3.63445.

Sistema de Informações Contábeis e Fiscais do Setor Público Brasileiro - SICONFI. (2018). Tabela: Receitas Orçamentárias (Anexo I-C). Imposto sobre a Propriedade Predial e Territorial Urbana, 2018. Recuperado em 23 de julho de 2019, de https://siconfi.tesouro.gov.br/siconfi/index.jsf

Slack, E., \& Bird, M. R. (2015). How to reform the property tax: lessons from around the world. IMFG Papers on Municipal Finance and Governance, 21, 1-30.

Smolka, M. O. (1991). Impostos sobre o patrimônio imobiliário urbano: aprimorando as informações e a sistemática de recolhimento. Ensaios FEE, 11(2), 442-454.

Smolka, M. O., \& Amborski, D. (2000). Value capture for urban development: An inter-American comparison. Cambridge, MA: Lincoln Institute of Land Policy.

Souza, M. L. (1998). Desenvolvimento urbano: a problemática renovação de um" Conceito" problema. Revista Território, 111(5), 5-29.

Tiebout, C. M. (1956). A pure theory of local expenditures. Journal of Political Economy, 64(5), 416-424. http://dx.doi.org/10.1086/257839.

Editor: Rodrigo Firmino

Recebido: Jul. 30, 2019

Aprovado: Abr. 22, 2020 